\title{
Food Taboos and Misconceptions Among Pregnant Women of Shashemene District, Ethiopia, 2012
}

\author{
Nejimu Biza Zepro \\ Department of Nursing, College of Health Sciences, Samara University, Samara, Afar, Ethiopia
}

Email address:

nejim76@gmail.com

To cite this article:

Nejimu Biza Zepro. Food Taboos and Misconceptions Among Pregnant Women of Shashemene District, Ethiopia, 2012. Science Journal of Public Health. Vol. 3, No. 3, 2015, pp. 410-416. doi: 10.11648/j.sjph.20150303.27

\begin{abstract}
Background: A food considered as a taboo is strictly forbidden, for health, cultural or spiritual reasons. Food taboos are known from virtually all human societies and may be found in various forms all over the world. Pregnancy is viewed as a critical period in the life of women and is usually subjected to a number of food taboos as a way of safeguarding their lives and that of the unborn baby. Poor maternal nutrition, especially in rural settings, adversely affects pregnancy and birth outcomes. In many local communities, pregnant women have food taboos with consequent depletion of vital nutrients. Malnutrition is one of the most serious health problems affecting children and their mothers in Ethiopia. As a result, there is lack of comprehensive information regarding practices and the factors associated with them in the study area. Therefore this study was aimed at measuring women who are likely to have certain taboos/misconceptions during pregnancy among pregnant women attending ANC services in public health institutions of shashemene district. Method: An institution based descriptive cross-sectional study design followed by Simple random sampling technique was used for 295 pregnant women, who are attending ANC service from public health institutions of Shashemene district. The Data was coded, entered in to EPI info 3.5.1 and exported to SPSS version 20.0 for further analysis. Frequencies, percentages, crude odds Ratio, $95 \%$ Confidence Intervals and multiple logistic-regressions were analyzed. Finally, the result of the study was presented using texts, figures and tables. Result: one half (49.8\%) of total pregnant mothers encountered food taboos at least for one food item. food items avoided were, linseed 92 times, honey 84 times, milk 67 times, fatty meat 63 times, eggs 50 times, fruits 41 times and vegetables 17 times. Reasons mentioned for avoidance of this food item; Plastered on the fetal head, makes fatty baby and difficult delivery, fear of abortion, evil eye, fetal abnormality. Educational status showed a significant association with belief of balanced diet. Conclusion: The study revealed that food taboos and traditional beliefs relating to pregnancy exist and larger proportion of women still believes in old unscientific tales. This can be improved by strengthening the nutrition counseling component of ANC which was inadequate in the ANC package received. Empowering community based health workers in providing effective nutrition counseling should be explored. There is a need for nutrition education and awareness generation among women; Increasing literacy status to reduce taboos/misconceptions.
\end{abstract}

Keywords: Food, Taboo, Misconceptions, Pregnant Women, Shashemene, Ethiopia

\section{Background}

Women and children are among the world most vulnerable in terms of unfavorable influences in the environment including insufficient nutrition, inadequate health care and poor education. In addition, Pregnancy brings those factors high risk for women. It is also common to hear pregnant women complain about changes in their appetites. Whereas some women report a dislike of or total aversion to specific foods, others report a strong craving for specific foods and non-food items, which are usually not readily accessible. [1]
Women and children are most vulnerable to poor nutritional status due to low dietary intakes, inequitable distribution of food, improper food storage and preparation $\&$ dietary taboos. [2]

Pregnant women who were not practicing taboos had significantly higher weight gain and heavier babies than women practicing strong food taboos in Nigeria. [3]

The World Health Report, 2003 states that, more attention should be given to maternal health and nutrition by governments and nongovernmental organizations. The United Nations meeting in 2006 clearly established that poor maternal nutritional status has to be improved in order to 
achieve the MDG 5 (reducing maternal mortality by three quarters in the years between 1990 and 2015). [4]

Feeding practices are differing from culture to culture and society to society. Consumption patterns are part of the culture of any given society and are related to traditions beliefs and taboos. Each culture whether traditional or modern, it has beneficial as well as harmful feeding practices In most cases women and children are highly affected by food habits and dietary discrimination. [5]

Results of other local and national nutritional surveys suggest that diets of mothers of low socioeconomic status are deficient in iron, zinc, and vitamins A and C. Therefore, it is indispensable that health professionals become more knowledgeable about the influence the culture has on breastfeeding, pregnancy and dietary behaviors and convictions that might be potentially harmful or dangerous during pregnancy and lactation. [6]

The study done in South India, Pondicherry out of 339, $216(63.7 \%)$ told that some vegetables/fruits should be avoided during pregnancy. There was no significant difference regarding this misconception between literates and illiterates. Most of the illiterates (91.3\%) told that papaya should not be eaten during pregnancy in comparison to $83.9 \%$ of literates. Most common reason for restriction of specified fruits/vegetables was abortion. [7]

In a study done by Puri $\mathrm{S}$ and Kapoor $\mathrm{S}$ it was reported that $16.5 \%$ of the adolescent girls believe that papaya can cause abortion. [8]

A study among 1200 women from all districts of Tamil $\mathrm{Nadu}$ in India showed that $82 \%$ of women avoided papaya during pregnancy. And also papaya is considered to be a fruit which is 'hot'. Conventionally 'hot' food items are avoided during pregnancy as it is thought that it will cause abortion. Similarly 'cold' foods are avoided during lactation as it might affect the quality and quantity of milk production. [9]

Brems and Berg from findings of 18 different cultures of food intake concluded that deliberate restriction of food intake during pregnancy is likely to have a small but significant effect on birth weight. In addition to cultural recommendations regarding an overall increase or decrease in food intake during pregnancy, particular foods may be encouraged or discouraged. An issue of concern however, is the fairly widespread practice of discouraging consumptions of protein during pregnancy. Several studies have found that meat, or meat from particular animals is specifically withheld, but most frequently from pregnant or lactating women [10, 18-221].

The more frequent taboo was related to the simultaneous consumption of milk and fruits, such as mango, orange, pineapple, and nuts. They also considered eating eggs and fruits together harmful, as well as a combination of meat with fish. They mentioned that "combinations are harmful", "combination kills", and "mixing together causes indigestion and vomiting." These restrictions were more frequent during the lactation period than during pregnancy. Food taboos adversely affect the daily consumption of protein, energy, and some nutrients during the first month of nursing [11].
In Sudan, pregnant women often have restricted food intake mainly due to morning sickness which is prevented and treated by eating little and limited items of food: and due also to the belief that a large fetus causing obstructed labor will result from eating unrestricted amount of food. In Sokoto state of Nigeria, the untrained traditional midwifes advice pregnant women to avoid sugar and honey as they cause prolonged painful labor. They also advise pregnant ladies not to take local soda which is supposed to make the fetus slim [12].

According to the ministry of health $(\mathrm{MOH})$ in Ethiopia, pregnant women a void specific food items due to several reasons: some pregnant women avoid as result of a strong dislike (aversion), other women avoid on medical grounds \& most due to cultural beliefs or impositions On this study, milk, eggs and goats meat are the major food items prohibited during pregnancy [10].

Study from Central statistical Authority of Ethiopia indicated that there are substantial numbers of pregnant women in developing countries who are obligated to avoid specific foods due to cultural beliefs or impositions in developing countries [13].

In most traditional society's food taboos are specifically directed toward women. The best and most nourishing portions of the food are served to the men. The nutritional deficiencies of most women are high particularly among pregnant and lactating women. Pregnant women are restricted from certain food staffs. For example, in the South South-Western and central part of Ethiopia, pregnant women are forbidden to take all foods which are white in color such as milk products, fatty meat, porridge and potato. Such foods are believed to be plastered on the body of the newly born baby. It is also assumed that the newly born baby and mother will have a bad smell if a pregnant woman eats vegetables. Green pepper is also prohibited with the assumption that a new born baby will become hairless. In the northern part of Ethiopia high carbohydrate and fat foods are forbidden for pregnant women with the assumption that it will bring about easier labor and smaller babies [11].

A study done on pregnant women in Hadiya zone, southern Ethiopia indicates that over half $(65 \%)$ avoided at least one type of food due to food taboos. According to this report milk and cheese were regarded as taboo foods by nearly half of the women $(44.4 \%)$ followed by linseed and fatty meat $(16 \%$, $11.1 \%)$ respectively. The reason for a voiding food includes fear of difficulty delivery $(51 \%)$, disclosures of the fetus $(20 \%)$ and fear of abortion $(9.75 \%)$ [1].

Food taboos and restriction of pregnant women from consuming certain kinds of food which is usually rich in the required nutrients leads to the low nutritional status among most women and put them at high risk of material death. Low body weight, iron deficiency and anemia are one of the main causes of death in case of hemorrhage during labor, and it is common among women in developing countries. For instance in Ethiopia, the mean height of women is only $156 \mathrm{~cm}$, indicating severe past malnutrition, and puts women at high risk in delivery, and $30 \%$ of non-pregnant women have a 
body mass index less than 18.5, which indicates serious chronic energy deficiency [14].

Much work regarding food taboos and misconceptions are not done on their impact on maternal and child nutrition. As a result, there is lack of comprehensive information regarding practices of food taboos. Therefore, this study was aimed at measuring women who are likely to have certain taboos/misconceptions among pregnant women attending ANC services in public health institutions of shashemene district.

\section{Methods and Materials}

\subsection{Study Setting}

Shashemene is a transition to many parts of Ethiopia, many rural and urban migrants are attracted for trading possibilities and seasonal employment and it is the most ethnically mixed district in Ethiopia, furthermore, the activities of informal sectors are targeted the large mobile people in the area

It is a road side district located in Oromiya administrative regional states, at Trans-African Highway to Cairo-Cape Town, about 160 miles $(250 \mathrm{~km})$ from the capital of Ethiopia, Addis Ababa, due south. Geographically, the district has latitude of $7^{\circ} 12^{\prime}$ north and a longitude of $38^{\circ} 36^{\prime}$ east. The study was carried out in all governmental health institutions of the woreda which provide ANC service for the entire community. Currently, there is 1 General hospital, 3 health centers, and 20 private health institutions in the district which are currently providing the service. According to the Central Statistical Agency in 2005, the total population of Shashemene was estimated to reach over 93,156, of whom 46,882 were males and 46,274 were females. Among those females $35.2 \%(16,288.5)$ were in reproductive age group (15-49), the total fertility rate was 4.2 .

Shashemene is different from other cities of Ethiopia by holding community of Rastafarians, who are Citizens from Jamaica, Trinidad and Tobago, Barbados, Saint Vincent, Grenada, Guyana, New Zealand, Canada, Germany, Sweden, Ghana, Kenya, Australia, Guadalupe and Suriname.

\subsection{Study Design and Population}

Cross-sectional descriptive study design was employed from February to March, 2012. The source populations were all pregnant women residing in the district .While, pregnant women coming for ANC service utilization were study populations.

\subsection{Sample Size Determination and Sample Procedure}

The sample size was determined by single proportion

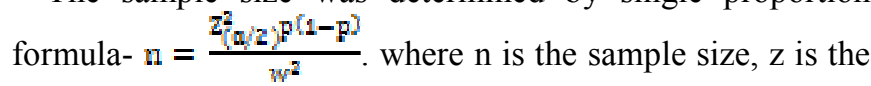
standard normal deviate, set at 1.96 (for $95 \%$ confidence level), $w$ is the desired degree of accuracy (taken as 0.05) and $\mathrm{p}$ is the estimate of the proportion of nutritional taboos (it is not known and assumed to be $50 \% \mathrm{p}=0.5)$. Thus, $\mathrm{n}=[1.962 \mathrm{x}$
$0.5(0.5) / 0.052]=384$, since the study population is less than 10,000 it was adjusted using the correction formula. nf $=\mathrm{N}($ no $) / 1+(\mathrm{N}($ no $) / \mathrm{N}) \mathrm{N}=$ estimate of the population size $(380)$ $n f=384 / 1+(384 / 1245)=295$.

Finally, the sample size was proportionally allocated to each public health facility. Then study subjects were selected systematic sampling, among proportionally allocated 295 pregnant women.

\subsection{Data Collection}

Data was collected using pretested structured questionnaire. The questionnaire was designed in English and translated to local language "Oromiffa" for better understanding by data collectors and interviewees. A total of four diploma holder Midwives and two Supervisors with qualification of BSc Nurse were hired.

\subsection{Data Analysis}

After the data collection, data was coded, entered, and cleaned on Epi Info version 3.5.4. Finally data was exported to SPSS version 20 for further analysis. Frequencies and cross tabulation were used for the descriptive analysis of the data. Associations between factors affecting nutritional practices and independent variables were analyzed. Both univariate and multivariate Analysis were made, in the binomial analysis, explanatory variables having a P-value less than or equal to 0.02 , variable having association in crude odds ratio, and variables shown association in different literatures was taken to multinomial analysis.

\subsection{Ethical Considerations}

Ethical clearance was also obtained from Internal Review Board of Addis Ababa University College of health science. Permission and verbal consent was obtained from the health institutions and study subjects respectively. Confidentiality was assured by excluding the names and specific identifiers of the study subjects'. The data was safeguarded during and after the data collection and no one except the principal investigator accessed the data.

\section{Result}

\subsection{Socio-Demographic Characteristics}

A total of 295 antenatal attendant women from Shashemene District were interviewed, 275 [93.2\%] were rural residents. More than half were above age of 24 years, $39 \%(115)$ and only $18.3 \%$ (54) women were above age of 35 years with the mean age of $27.5+6.3$ years.

The major ethnic groups among respondents were Oromo (56.9\%), by Ethnicity and Muslims (61\%) by religious doctrine, and the majority $(93.2 \%)$ of the women were married.

Educationally, half of women $52.2 \%$ cannot read and write while $(13.9 \%)$ had attended secondary and above. Greater than half (56.4\%) of the study subjects had a monthly income 
below 500 birr and housewives by occupation. [Table 1]

Table 1. Socio-demographic characteristics of ANC attendants in Shashemene district; March, 2012

\begin{tabular}{|c|c|c|}
\hline Variables & Frequency & Percent (\%) \\
\hline \multicolumn{3}{|l|}{ Residence } \\
\hline Peri urban & 20 & 6.8 \\
\hline Rural & 275 & 93.2 \\
\hline \multicolumn{3}{|l|}{ Age $(\mathrm{N}=295)$} \\
\hline $15-24$ & 115 & 39 \\
\hline $25-34$ & 126 & 42.7 \\
\hline$>35$ & 54 & 18.3 \\
\hline Mean + SD & & $27.5+6.3$ \\
\hline \multicolumn{3}{|l|}{ Religion } \\
\hline Muslim & 180 & 61 \\
\hline Orthodox & 78 & 26.4 \\
\hline Protestant & 37 & 12.5 \\
\hline \multicolumn{3}{|l|}{ Education } \\
\hline No schooling & 154 & 52.2 \\
\hline Primary & 100 & 33.9 \\
\hline secondary and above & 41 & 13.9 \\
\hline \multicolumn{3}{|l|}{ Marital status } \\
\hline Unmarried & 20 & 6.8 \\
\hline Married & 275 & 93.2 \\
\hline \multicolumn{3}{|c|}{ Monthly income $(n=172)$} \\
\hline$<=200$ birr & 19 & 11 \\
\hline 201-500 birr & 78 & 45.3 \\
\hline 501-1000birr & 53 & 30.8 \\
\hline$>1000$ birr & 22 & 12.8 \\
\hline Mean +SD & & $698+576.4481$ \\
\hline \multicolumn{3}{|l|}{ Occupation } \\
\hline House wife & 164 & 54.6 \\
\hline Civil servant & 48 & 16.3 \\
\hline Farmer & 24 & 8.5 \\
\hline Merchant & 35 & 12.5 \\
\hline Others & 19 & 6.3 \\
\hline
\end{tabular}

\subsection{Reproductive Characteristics}

About $80.7 \%$ interviewed women were multigravida with $3+$ SD 1.89 median numbers of births and more than $85 \%$ of the respondents had no history of abortion or stillbirth (Table 2).

Table 2. Reproductive history of women attending ANC services in Shashemene district, March, 2012.

\begin{tabular}{lll}
\hline Variables & Frequency & Percent (\%) \\
\hline Gestation & & \\
First trimester & 78 & 26.4 \\
Second trimester & 180 & 61.0 \\
Third trimester & 37 & 12.5 \\
Number of birth & & \\
Primi (<=1) & 56 & 19 \\
Multi (2-4) & 156 & 52.9 \\
Grand para (>=5) & 83 & 28.1 \\
Ever had Abortion & & \\
No & 255 & 86.4 \\
Yes & 40 & 13.6 \\
Ever had Still birth & & \\
No & 252 & 85.4 \\
Yes & 43 & 14.6 \\
Previous ANC & & 63.2 \\
Yes & 151 & \\
No & 88 & \\
\hline
\end{tabular}

\subsection{Food taboo during Pregnancy}

Almost half (49.8\%) of the respondents avoid one or more food items during pregnancy. Linseed, Honey and Milk/ yoghurt were commonly avoided food items. Belief for food restriction were Plastered on the fetal head, makes fatty baby and difficult delivery, fear of abortion, evil eye, fetal abnormality. More than three forth $(82.4 \%)$ believe on importance of eating balanced diet during pregnancy. but only $33.2 \%$ made changes to their normal eating habit.

More than one third $(38.3 \%)$ of pregnant women practice fasting during pregnancy, type of fasting includes restriction of meat and milk containing food items in orthodox religion and Abstain from eating at day time in Muslim women. (Table 3)

Table 3. Food taboos in pregnant women attending ANC service in Shashemene district, March 2012.

\begin{tabular}{|c|c|c|}
\hline $\begin{array}{l}\text { Nutrition during pregnancy }(\mathrm{N}=295) \\
\text { Importance of balanced diet }\end{array}$ & number & percent $(\%)$ \\
\hline Yes & 243 & 82.4 \\
\hline No & 52 & 17.6 \\
\hline \multicolumn{3}{|l|}{ Change in feeding habit } \\
\hline Yes & 98 & 33.2 \\
\hline No & 197 & 66.8 \\
\hline \multicolumn{3}{|l|}{ Fasting during pregnancy } \\
\hline Yes & 113 & 38.3 \\
\hline No & 182 & 61.7 \\
\hline \multicolumn{3}{|l|}{ Foods aversion during pregnancy } \\
\hline Yes & 147 & 49.8 \\
\hline No & 148 & 50.2 \\
\hline \multicolumn{3}{|l|}{ Food items averted $(n=147)$} \\
\hline Milk/ yoghurt & 67 & 22.7 \\
\hline Egg & 50 & 16.9 \\
\hline Fatty Meat & 63 & 21.4 \\
\hline Honey & 84 & 28.5 \\
\hline Linseed & 92 & 31.2 \\
\hline Fruits & 41 & 13.9 \\
\hline Vegetables & 17 & 5.8 \\
\hline Reasons for food taboo $(n=147)$ & 91 & 30.8 \\
\hline $\begin{array}{l}\text { Plastered on the fetal head Fear of fatty baby } \\
\text { and difficult delivery }\end{array}$ & 90 & 30.5 \\
\hline Others (fear of fetal abnormality, Abortion) & 12 & 4.1 \\
\hline
\end{tabular}

\subsection{Factors Associated with Maternal Nutrition during Pregnancy}

Importance of balanced diet during pregnancy was found to have significant association with Age, educational status, and previous ANC attendance. Women who can read and Write were 5 times more likely to have knowledge of balanced diet than illiterate women and younger women were more likely to attend ANC and health education than their counterpart. Previous experience of ANC attendance was 3 times more in position to belief on the importance of balanced diet. (See Table 4) 
Table 4. Socio-demographic factors associated with food taboo in public health institutions of Shashemene district, March 2012.

\begin{tabular}{|c|c|c|c|c|c|}
\hline \multirow[t]{2}{*}{ variables } & \multicolumn{2}{|c|}{$\begin{array}{l}\text { balanced } \\
\text { diet use }\end{array}$} & \multirow[t]{2}{*}{ COR 95\%CI } & \multirow{2}{*}{$\begin{array}{l}\text { AOR 95\% } \\
\text { CI }\end{array}$} & \multirow{2}{*}{$\begin{array}{l}p- \\
\text { value }\end{array}$} \\
\hline & Yes & No & & & \\
\hline \multicolumn{6}{|l|}{ Age group } \\
\hline $15-19$ & 14 & 4 & & & \\
\hline $20-24$ & 86 & 11 & $\begin{array}{l}3.062(1.297- \\
7.232)\end{array}$ & & 0.011 \\
\hline $25-29$ & 80 & 11 & $\begin{array}{l}3.292(1.397- \\
7.759)\end{array}$ & & 0.006 \\
\hline $30-34$ & 25 & 10 & $\begin{array}{l}1.474(0.42- \\
5.171)\end{array}$ & $\begin{array}{l}0.175(0.001 \\
-3.812)\end{array}$ & 0.049 \\
\hline$>=35$ & 38 & 16 & 1.00 & 1.00 & \\
\hline \multicolumn{6}{|l|}{$\begin{array}{l}\text { Educational } \\
\text { status }\end{array}$} \\
\hline Illiterate & 116 & 38 & 1.00 & 1.00 & \\
\hline $\begin{array}{l}\text { Can read and } \\
\text { write }\end{array}$ & 59 & 2 & $\begin{array}{l}9.664(2.253- \\
41.444)\end{array}$ & $\begin{array}{l}5(1.212- \\
2.682)\end{array}$ & 0.40 \\
\hline $\begin{array}{l}\text { Primary }\left(1-8^{\text {th }}\right. \\
\text { grade })\end{array}$ & 29 & 10 & & & \\
\hline Secondary & 26 & 1 & $\begin{array}{l}8.517(1.118- \\
64.89)\end{array}$ & & 0.39 \\
\hline $\begin{array}{l}\text { College and } \\
\text { above } \\
\text { Monthly } \\
\text { income }\end{array}$ & 13 & 1 & & & \\
\hline$<=200$ & 14 & 5 & 1.00 & & \\
\hline $201-500$ & 71 & 7 & $\begin{array}{l}3.622(1.004- \\
13.065)\end{array}$ & & 0.049 \\
\hline $501-1000$ & 46 & 7 & & & \\
\hline$>=1000$ & 19 & 3 & & & \\
\hline \multicolumn{6}{|l|}{ Previous ANC } \\
\hline yes & 139 & 12 & $\begin{array}{l}7.293(3.517- \\
15.123)\end{array}$ & $\begin{array}{l}3.125 \\
(1.178- \\
8.291)\end{array}$ & 0.022 \\
\hline No & 54 & 34 & 1.00 & 1.00 & \\
\hline \multicolumn{6}{|l|}{$\begin{array}{l}\text { Change in } \\
\text { feeding habit }\end{array}$} \\
\hline Yes & 95 & 3 & $\begin{array}{l}10.484 \\
(3.177- \\
34.595)\end{array}$ & & 0.000 \\
\hline $\begin{array}{l}\text { No } \\
\text { Fasting during } \\
\text { pregnancy }\end{array}$ & 148 & 49 & 1.00 & & \\
\hline Yes & 103 & 10 & $\begin{array}{l}3.090(1.482- \\
6.445)\end{array}$ & & 0.003 \\
\hline No & 140 & 42 & 1.00 & & \\
\hline
\end{tabular}

\section{Discussion}

This study assessed common food taboos and misconceptions during pregnancy. Study subjects were between the age of 20-34 years with mean age of 27.5 and + 6.3 years. Compared to (EDHS, 2005) this study subjects are younger. On the other hand more than half $(52.2 \%)$ of the interviewed women were illiterate which is inconsistent with (EDHS 2005) report. Almost half 147(49.8\%) of study participants were obligated to avoid one or more food items during pregnancy. this study shows double increment from other study done in Adama town which was only $23.7 \%$ and this finding was relatively lower than study done in Hadiya zone $(65 \%)$ [1].
Importance of balanced diet was found to be significantly associated with age groups, educational status, and previous ANC attendance. As age of the women increases, the belief on the importance of balanced diet decreases showing a significant association of 0.175 (0.001-3.812). Consistent with other studies, women younger than 35 years are more likely to attend ANC and health education. The possible explanation could be; younger women may be more likely to accept modern health services since; they are more energetic, more likely to attend formal education. Older women on the other hand, tend to believe on indigenous knowledge of traditional practice thus giving less attention to feeding balanced diet and ANC follow up. In addition aged women are more likely to have more children to care for; the 2005 EDHS also indicated women below 35 are more likely to utilize prenatal care than the elderly [16].

Educational status and previous ANC attendance of the women also showed significant association with belief on balanced diet with an adjusted odds ratio of 5.0 (1.212-2.682) and $3.125(1.178-8.291)$ respectively. This may be due to knowledge gain from formal education and experienced health education during ANC care may improve the awareness of those mothers to feed balanced diet during pregnancy.

Feeding practices are differing from culture to culture and society to society. Consumption patterns are part of the culture which is related to traditions beliefs and taboos. Food habits are mainly determined by the availability of indigenous food supply, socio-cultural and educational orientation of food processing and preparation methods. Each culture whether traditional or modern, it has beneficial as well as harmful feeding practices. In most cases women and children are highly affected by food habits and dietary discrimination [5].

Concerning diet changes during pregnancy, only $33.2 \%$ of all respondents have made changes of their normal eating habit compared to non-pregnancy period. The responded feeding changes include increasing feeding frequency (26.1) \%, eating more carbohydrate $(21 \%)$, were reported more frequently. studies in Sudan indicated that one of the reasons given to avoid eating different diet items were; food items make the pregnant women fat so that their birth canal will be narrowed making difficult labor. This reason is not scientifically justifiable as there is no association between the foods eaten and direct attachment to the fetus, or narrowing of the birth canal. Study findings with higher percentage and variety of food restriction are in line with this study $[10,1]$. but more than half $(66.8 \%)$ did not have change in feeding habit from non-pregnancy period which together with the above factors worsen the nutrient supply of the mother as well as the fetus.

The more frequent taboo reported were simultaneous consumption of linseed (92 times), honey (84 times), milk (67 times) and fruits, such as mango, orange, Avocado, pineapple, and nuts. They also considered mixing eggs and fruits together as harmful, as well as a combination of meat with cheese was also reported to be harmful for the fetus as 
well as the mother. The reasons to these food taboos were; plastered on the fetal head, fatty baby, fear of abortion and still birth. This finding is consistent with the study done in Hadiya zone [1]. Food taboos adversely affect the daily consumption of protein, energy, and other essential nutrients [11]. Food restrictions were significantly associated with Ethnicity, Oromo ethnic groups were shown to have much food taboos than wolyta ethnic groups with an adjusted odds ratio of $14.988(1.681-133.644)$ at $95 \% \mathrm{CI}$.

\section{Limitations of the study}

- Design Limitation in establishing the cause and effect relationship

- Very limited studies for further comparison and discussion

- Absence of qualitative findings for possible triangulation

\section{Conclusion and Recommendations}

The study revealed that food taboos and misconceptions governing pregnancy exist in shashemene woreda. One half $(49.8 \%)$ of women in the study area were obligated to avoid specific food items due to cultural and traditional views. Less educated women were, the more they practice food taboos. The less educated women were, the more likely to observe more food taboos. This observation underscores the importance of educating women and providing nutrition education aimed at changing mothers' attitudes towards appropriate feeding practices.

Pregnant women living in rural settlements have more food taboos and misconceptions. This may be improved by strengthened nutritional counseling program. Empowering health extension workers in providing effective nutrition counseling should be explored given the overburdened public health system.

$\mathrm{MCH}$ clinics must play a leading role in coordinating this effort of awareness creation. They should also put mechanisms that can routinely identify women observing food taboos, assess the reasons and provide appropriate nutrition education. Other governmental and nongovernmental organizations and various public associations, such as women's Associations should also be actively involved in eliminating these harmful beliefs. Pregnant women should be encouraged "eating up" during pregnancy and to provide supplementary food to poor women who cannot afford. In addition, the health education programs should take cognizance of the popular beliefs regarding food during pregnancy and use innovative means to minimize their negative and maximize their positive nutritional effects. In a bid to address every aspect of maternal health care, researchers should expand the objectives of their research to include nutritional taboos and misconceptions, outline the corresponding health implications and conduct same to reflect nation relevance.

\section{List of Abbreviations}

\author{
AA: Addis Ababa \\ ACOG: American College of Obstetrics and Gynecology \\ ANC: Antenatal care \\ AOR: Adjusted odds ratio \\ CSA: Central Statistical Agency \\ COR: Crude odds ratio \\ EDHS: Ethiopian Demographic Health Survey \\ HTTP: Harmful Traditional Practice \\ MCH: Maternal and Child Health \\ MM: Maternal Mortality \\ MOH: Ministry of Health \\ MDG: Millennium Development Goal \\ PMTCT: Prevention of Mother to Child Transmission \\ SNNPR: South Nation Nationalities People Region \\ UN: United Nation \\ WHO: World Health Organization
}

\section{Acknowledgement}

My deepest gratitude and appreciation goes to both Addis Ababa and Samara Universities for their academic instructions and financial support to undertake my study. I am thankful to all study participants, data collectors and supervisors for their genuine co-operation. I am also delighted to acknowledge Shashemene district public health institutions, Last but not least, I am also thankful to Engida Yisma, Lecturer in School of Nursing and Midwifery, Addis Ababa University, Addis Ababa, Ethiopia for his technical advice and contributions during manuscript preparation.

\section{References}

[1] Demisse T. Murok N.,etal, food taboos among pregnant women in Hadiya zone, Ethiopian journal of health development, v12, No1, April 1998.24. Sevenhuyen G.P and W/Gebriel z.

[2] CSA, ORC Macro. Ethiopia Demographic and Health Survey, Addis Ababa, Ethiopia and Calverton, Maryland, USA: September; 2005Mihret H., Mesganaw F., Birth preparedness \& complications readiness among women in Adigrat town, North Ethiopia: Ethiopian journal of health development, volume22, no.1, 2008, 1-96.

[3] CSA, ORC Macro. Ethiopia Demographic and Health Survey, Addis Ababa, Ethiopia and Calverton, Maryland, USA: September; 2005.

[4] WHO, Magnitude of Reproductive health problems, International journal, 2003.

[5] African Center for Women (1997) Traditional and Cultural Practices Harmful to the Girl- Child, A cross Sectional Review No.1, Economic Commission for Africa.

[6] Food Taboos among Nursing Mothers of Mexico: Maria Irene Santos-Torres and Edgar Vásquez-Garibay,J HEALTH POPUL NUTR 2003 Jun; 21(2):142-149. 
[7] RajkumarPatil, Anuj Mitta, etal Taboos and misconceptions about food during pregnancy among rural population of Pondicherry. Calicut Medical Journal 2010;8(2):e4.

[8] Ankita Parmar etal, A study on taboos and misconceptions associated with pregnancy among rural women of Surendranagar district.

[9] Nag, Moni.: Beliefs and Practices About Food During Pregnancy. Economic and Political Weekly. Sept 10, 1994. P.2427-2438.

[10] Ministry of planning and economic development, Food and nutrition unit, social and cultural aspects of food consumption patterns in Ethiopia, Addis Ababa,1992.

[11] Christian Relief and Development Association (1991) Workshop on Nutrition and Family Health, Christian Relief and Development Association, Ethiopia
[12] Scholl T.o, Hedger M.L, etal, Low zinc intake during pregnancy: its association with preterm labour, American journal of epidemiology, 1993:137(10):1115-1124.

[13] Central statistical Authority 2004, Ethiopian Demographic and Health Survey, Addis Ababa, 2006.

[14] National Committee on Traditional Practices of Ethiopia (2003) Old Beyond Imagining: Ethiopian Harmful Traditional Practices, Addis Ababa, Ethiopia.

[15] Ethiopia Demographic and Health Survey (EDHS) 2005 Preliminary Report. 